\title{
Fluency Differences by Text Genre in Proficient and Struggling Secondary Students
}

\author{
David Paige ${ }^{1}$, Theresa Magpuri-Lavell1, Timothy Rasinski², Willam Rupley ${ }^{3}$ \\ ${ }^{1}$ Bellarmine University, Louisville, KY, USA \\ ${ }^{2}$ Kent State University, Kent, OH, USA \\ ${ }^{3}$ Texas A \& M University, College Station, TX, USA

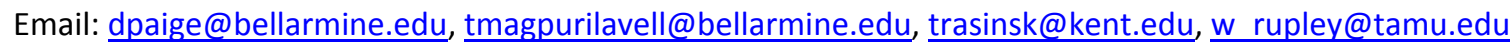

Received 25 August 2015; accepted 10 October 2015; published 13 October 2015

Copyright (C) 2015 by authors and Scientific Research Publishing Inc.

This work is licensed under the Creative Commons Attribution International License (CC BY). http://creativecommons.org/licenses/by/4.0/

(c) (i) Open Access

\begin{abstract}
Reading fluency has been found to be an essential component of proficient reading and is a significant part of the Common Core State Standards (CCSS, 2010; NRP, 2000). Previous research has found that students may often differ in their ability to fluently read narrative and informational text. In this study we examine differences in fluent reading by text-genre in a sample of 108 ninth-grade readers. We also investigate these same differences based on whether a student is a proficient or struggling reader. Results for the total sample of readers show that oral reading fluency is more languid when students read informational texts. Additionally, large differences are found when readers are blocked as either proficient or struggling. Instructional implications are discussed.
\end{abstract}

\section{Keywords}

Fluency, Text-Genre, Secondary Students, Narrative, Informational Text

\section{Introduction}

Embedded within the Common Core State Standards (CCSS, 2010), that are currently operational in 44 states and the District of Columbia (National Governors Association Center and Council of Chief State School Officers, 2012), is the requirement that students be able "to read and comprehend independently and proficiently the kinds of complex texts commonly found in college and careers” (p. 2, Appendix A). Understanding the ramifications of this requirement entails examination of several key terms including those of "to read and comprehend”, and to do so "independently and proficiently” (p. 2, Appendix A). To read and comprehend partitions the 
reading process along the simple view of reading (Hoover \& Gough, 1990) that represents comprehension as the product of decoding plus linguistic comprehension. Reading texts proficiently suggests to us that necessary foundational fluency competencies must be in place that enables readers to focus their cognitive resources on creating meaning from the text (McCormick \& Samuels, 1979; Perfetti \& Hogaboam, 1975; Samuels \& Farstrup, 2006). This suggests that there is a reciprocal relationship between fluency and comprehension while fluency has been repeatedly shown to be a necessary condition for effective comprehension (Paige, 2011a; Fuchs, Fuchs, Hosp, \& Jenkins, 2001; Jenkins, Fuchs, Espin, van den Broek, \& Deno, 2003a, 2003b; Kuhn \& Stall, 2003; Pinnell, Pikulski, Wixon, Campbell, Gough, \& Beatty, 1995; Schatschneider, Buck, Torgesen, Wagner, Hassler, Hecht et al., 2004; Stecker, Roser, \& Martinez, 1998; Young, Bowers, \& MacKinnon, 1996). A major shift within CCSS is the increased importance of comprehending informational texts across grade levels. This shift presents a problem in need of close examination of importance to middle and secondary educators, and can students read both narrative and informational texts with similar levels of fluency? The purpose of this study is to explore the extent to which differences in fluency rates exist when secondary students read to comprehend narrative and informational text.

\subsection{Expectations and Current Outcomes}

Common Core State Standards (2010) call for using an equal distribution of narrative and informational text across grades kindergarten through five. This text distribution increases to $30 \%$ narrative and $70 \%$ informational in grades six through twelve. Narrative texts are written to "tell a story" (Weaver \& Kintsch, 1991: p. 230). Informational genres are written to inform and assist the reader in learning something new (Weaver \& Kintsch, 1991). Therefore, to promote and enhance learning, they use different organizational and language structures from those used in narrative genres (Goldman \& Rakestraw, 2000; Kucan \& Beck, 1996; Meyer \& Rice, 1984; Olson, Mack, \& Duffy, 1981). Furthermore, these structures vary from one disciplinary area to another. For example, in science text the organizational feature and language of vocabulary are precise and have narrower parameters of meaning (Rupley\& Slough, 2010). Social study texts, on the other hand, are more similar to narrative text, yet are still focused on acquisition of content knowledge (Paige, 2011a).

The ability to read text critically and answer text-dependent questions is central to Common Core expectations. Unfortunately, such capabilities are sorely lacking in students. For example, $64 \%$ of eighth-grade students taking the 2013 National Assessment of Educational Progress scored at or below the basic level (National Center for Educational Statistics, 2013). The College Board (2014) has recently redesigned the SAT college entrance exam to more accurately assess skills encouraged through implementation of the Common Core (Lewin, 2013). In 2012, 51\% of students taking the SAT failed to achieve a reading score indicating college readiness. Similarly, in the most recent report from ACT (2013), only 44\% of students taking this college entrance exam scored as college-ready in reading. In an interesting paradox, a survey of high school seniors found that while the large majority felt they possessed literacy skills to successfully encounter college-level reading, they also reported a low tolerance for engaging in long periods of reading, particularly with informational texts (Hooley, Tysseling, \& Ray, 2013). In sum, the expectation for college- and career-ready reading, which heavily relies on processing informational text, is far from being met. At the same time, the Common Core State Standards are clear in noting that students must have command of both narrative and informational text and be able to process both at a deep level of comprehension. As such, an investigation into the degree to which students read narrative and information text fluently has potential to further inform and advance the quality of literacy instruction.

\subsection{Importance of Fluent Reading}

So where does fluent reading enter into the discussion of reading differences between narrative and informational text? The construct of fluent reading can be represented as reading with (1) word recognition accuracy, which is the foundation for appropriate pacing (automaticity), and (2) comprehension of text as reflected in prosody (expression) (Paige, Rasinski, Magpuri-Lavell, \& Smith, 2014). Although the development of reading fluency has been traditionally viewed as a critical competency developed in the elementary grades (Chall, 1983), recent research suggests a broader view that extends into the middle and secondary grades. In a study of oral reading fluency, Pinnell et al. (1995) found that approximately $44 \%$ of students who scored poorly on the reading portion of the National Assessment of Educational Progress (NAEP) (a silent reading comprehension assessment) were disfluent in their oral reading. Ten years later a replication of that study found similar results further em- 
phasizing the indispensable connection between fluency and comprehension; furthermore, far too many students were failing to become fluent readers (Daane, Campbell, Goodman, Grigg, \& Oranje, 2005).

Additional studies support the importance of reading fluency in middle and secondary grades. An investigation of students' fluency who were attending an urban middle school found that not only were students' oral reading fluency skills well below grade level, but that oral reading fluency accounted for $50 \%$ of the variance in their silent reading comprehension (Paige, 2011a). In a study focused on secondary students, Rasinski et al. (2005) found that $61 \%$ of ninth-grade students attending a Title I school scored at the 25th percentile on eighth-grade reading norms. In another study of ninth-grade students attending an urban school, Paige \& Magpuri-Lavell (2011b) found that students' fluency skills were generally two or more years below grade level expectations. More recent research has found that prosody, a component of reading fluency, was the largest predictor of comprehension in secondary students (Paige, Rasinski, \& Magpuri-Lavell, 2012; Paige, Rasinski, Magpuir-Lavell, \& Smith, 2014).

Collectively, these studies support that the ability to fluently read text is an important component of reading performance in the middle and secondary grades. Fluent reading that supports oral reading comprehension also engages the same reading mechanisms that enhance silent reading comprehension (Taylor, 2011). Investigations (Kelley \& Clausen-Grace, 2006; Kim \& White, 2008; Reutzel, Fawson, \& Smith, 2008) have also demonstrated that silent reading fluency can be improved through scaffolded reading interventions, thus showing that practice with text, whether completed orally or silently, has a positive impact on the development of both oral and silent reading fluency and comprehension.

\subsection{Fluency Differences by Text-Genre}

The question arises as to whether or not fluency differences might exist between text-genre, and if so, why should we be concerned? Conventional wisdom has suggested for decades that informational text is more difficult to read and understand than narrative text and indeed, ample studies support this notion (Best, Floyd, \& McNamara, 2008; Braten \& Oistein, 2013; Diakidoy, Stylianou, Karefillidou, \& Papageorgiou, 2004; Read, Reutzel, \& Fawson, 2008). However, few empirical studies have investigated fluency differences between narrative and informational text. One such study (Best et al., 2008) focused on third-grade students' decoding and comprehending of narrative and informational texts. The authors found that decoding skills best predicted comprehension of narrative, but not informational text. Sáenz \& Fuchs (2002), examined 111 high school males (mean age $=16.17$ years) with reading disabilities whose reading levels ranged from the second- to sixth-grades. Students were measured on the number of words-read-correctly during two-minute readings of narrative and informational texts. Results showed that the mean number of words read correctly was significantly greater for narrative (223.16) than for informational text (212.62). Lastly, a study of third- and fourth-graders, about half of whom were ELLs and half fluent English speakers, compared their readings of narrative and informational texts and found that accuracy and comprehension were similar across both text-genres (Cervetti, Bravo, Hiebert, Pearson, \& Jaynes, 2009). While these studies provide some support that narrative text is read more fluently than informational text, the results are mixed. Additionally, no studies have investigated whether the effect of text-genre extends equally to both proficient and struggling readers.

Exposure and opportunity to read informational texts increases as students progress through the grades. Since practice is supported as an essential method for improving fluency, it is reasonable to think that as students move beyond the primary grades, fluency with informational text will improve and possibly approach the level of narrative texts. The present study attempts to determine if a fluency gap exists between narrative and informational text reading among secondary students.

\subsection{Theoretical Framework}

Graesser, Millis, \& Zwaan (1997) propose five levels or "compositional components” of discourse comprehension. These levels consist of surface code, textbase, situation model, genre of the text and its rhetorical structure, and communication pragmatics. Surface code consists of the various phonemic and phonological structures that make up words, as well as the various syntactic structures dictating how words are ordered within text. The textbase consists of explicit propositions, referents, and inferential connectives linking text, which together function to preserve meaning and maintain coherence. The situation model consists of the agents within the text, the various temporal, spatial, causality, and intentionality dimensions that occur, inferences that bridge ideas, and the mental images and models described in the text. The fourth level accounts for the genre and rhetorical structure 
used by the author and is what distinguishes the text as narrative, persuasive, informational, or descriptive. The fifth level of discourse comprehension reflects the communication pragmatics that guides the goals and attitudes of the speaker or writer. Graesser \& McNamara (2011) suggest these levels reflect a compositional viewpoint to which is attached a "knowledge and process point of view" (p. 373). The latter reflects the notion that the reader must have sufficiently developed mental or cognitive processes relevant to each of the five levels, without which, breakdowns in comprehension processing will occur. Consequently, discourse compositional components provide a theoretically rich resource from which to hypothesize differences in decoding proficiency based on text genre. Compared to narrative texts, informational texts often have greater structural complexity that places greater demand on cognitive processing (Stein \& Trabasso, 1981). For example, text genre may present unfamiliar syntax and text structure to the reader that can make comprehension more difficult (Langer, 1986).

The tandem theory of reading (Paige et al., 2014) has been proposed to explain relationships among word recognition accuracy, word recognition pacing (automaticity), and prosody in conjunction with comprehension when reading text aloud or silently. The theory first assumes that the goal for reading is to understand the text, and that in pursuit of understanding the reader adequately monitors for comprehension. Assuming the reader's goal is comprehension and that effective monitoring is taking place, the theory hypothesizes that the fluency indicators of accuracy, pacing, and prosody work together to maximize comprehension. However, the three indicators work in different ways. Word recognition accuracy is hypothesized to be maximized when the reader attempts to correctly decode words. Prosody is reasoned to help the reader better understand the text by aiding the integration of information across clauses and sentences (Bader, 1998; Slowiaczek \& Clifton, 1980; Walther et al., 1999), while also assisting with syntactic ambiguity (Fodor, 2002). What is not always maximized is pacing, the third indicator of fluent reading. The model hypothesizes that the reader intentionally regulates reading pace to maximize comprehension. As such, the reader may invoke a reduction in pacing to adjust for challenges to comprehension caused by any of the compositional components proposed by Graesser et al. (1997). When comprehension comes easily, the reader may also choose to increase pacing. In their study of eye movements during reading, Just \& Carpenter (1980) suggest that texts may contain dense or potentially multiple meanings causing semantic ambiguity that would manifest itself in reduced pacing (see Rayner, Pollatsek, Ashby, \& Clifton, 2012 for a full discussion). As such, it is reasonable to expect that text characteristics attributable to genre may potentially manifest themselves in reading fluency differences.

Within the fluency literature indicators of word identification accuracy and pacing are combined into a quantitative metric called words-correct-per-minute (WCPM). This metric is calculated by subtracting reading miscues from the total words read (both correctly and incorrectly). In the present study, rather than a metric based on words-correct-per-minute, we measure the total words read correctly during a 3-minute reading. For the remainder of this study we will refer to this metric as accumaticity, a blending of the terms word recognition accuracy and automaticity.

In this study, we are investigating the influences on text-genre for two of the indicators of fluent reading in a sample of ninth-grade readers. As such, we seek to answer the following research questions:

1) Do differences attributable to text-genre exist for measures of word accuracy, pacing, and accumaticity?

2) To what extent do struggling and proficient readers differ on measures of accuracy, pacing, and accumaticity when reading narrative and informational genre?

Although prosody is also a significant indicator of reading fluency, it is generally measured subjectively by the use of rubrics. Inasmuch as the present study is foundational in comparing reading narrative and informational genres, we chose to focus on the fluency variables that were most accessible to objective measurement.

\section{Method}

\subsection{Participant Selection}

Our first step for acquiring research participants involved gaining permission from the parents of ninth-grade students attending an orientation session that was held prior to the start of school. Informed parental consent was obtained from 52 parents agreeing to allow their children to participate. Our next step entailed meeting with each of the ninth-grade homeroom classes shortly after the start of school to explain the study to students, including its benefits and risks, and to ask them to consider participating. This resulted in an additional 56 students returning informed consent from their parents for a convenience sample of 108 participants. 


\subsection{Participant Description}

Participants for this study were drawn from the ninth-grade of a high-poverty secondary school in a large metropolitan district. As a whole, students attending this school struggle with literacy achievement and consistently score near the bottom on statewide, end-of-year reading assessments. The average student age at the time of the study was 14 years, 5 months. Of the students attending the study school, approximately $88.0 \%$ received free- or reduced-priced lunch with $77.8 \%$ residing in a one-parent household. Of the 108 students in the study, 47 (43.5\%) were female and 61 (56.5\%) were males. Of these, 49 were of Caucasian ethnicity (45.3\%), 54 (50.0\%) of African American ethnicity, and 5 (4.6\%) of either Hispanic or Asian ethnicity. Of the 108 students, six (5.6\%) received services for mild to moderate learning disabilities.

\subsection{Text Readability Measures}

The reading theories reviewed earlier suggest the efficiency with which a reader processes text is influenced by the readability characteristics of that particular text. Spiro \& Taylor (1980) suggest that text readability can be classified by the degree to which it possesses the characteristics that influence cognitive processing. Appendix A of the Common Core State Standards (CCSS, 2010) for English Language Arts describes an approach for determining the readability of a text and describes three dimensions consisting of qualitative, quantitative, and reader and task considerations that determine the readability of a text. Qualitative and quantitative considerations focus on the internal complexity of the text. Reader and task considerations focus on the motivation and background knowledge of the individual reader, and the purpose for which the text will be used. Potential texts for this study were subjected to qualitative, quantitative, and reader and task evaluations to distinguish the genre as either narrative or informational. To assess the qualitative and reader and task dimensions of the texts under consideration, we consulted with the ninth-grade social studies faculty at the study school. The faculty reviewed and determined which texts would be most appropriate from the texts that had been previously graded on their quantitative characteristics. The criteria used for grading each text were those recommended by CCSS, Appendix A which includes considerations for 1) levels of meaning (narrative) or purpose (informational); 2) text structure; 3) language conventions and its clarity; and 4) knowledge demands of the text. At the conclusion of the evaluation two texts genres, one narrative and one informational were chosen by the teachers as appropriate for ninthgrade readers.

One way to measure text readability is through the use of quantitative readability tools. Two such tools used to evaluate texts in the present study are the Coh-Metrix Text Easability on-line tool (Graesser, McNamara, \& Kulikowich, 2011; Graesser, McNamara, Louwerse, \& Cai, 2004) and the ATOS Readability tool (Renaissance Learning, 2014). Coh-Metrix provides an overall readability measure calculated using the Flesch-Kincaid formula (Flesch, 1951) that converts the Flesch Reading Ease formula to a U.S. grade level. Text readability is interpreted where text complexity increases concurrently with grade level. Coh-Metrix also provides measures of five textual characteristics. Narrativity is the extent to which the passage is story-like and reflects everyday language, while syntactic simplicity measures the use of familiar syntax that is easier for readers to process and comprehend. Word concreteness gives the percentage of concrete versus abstract words contained in the text. Concrete words provide the reader with evocative mental images, the use of which makes a text easier to comprehend. Referential cohesion measures the extent to which overlapping words and ideas are present between sentences and across text, the more liberal use of which assists the reader with text comprehension. Finally, deep cohesion exists when a text makes intentional connections between causal and logical relationships. This type of cohesion assists the reader in connecting various causal events and actions occurring across the text.

The ATOS Readability Formula (Milone, 2012; Nelson, Perfetti, Liben, \& Liben, 2012; Renaissance Learning, 2014) analyzes a text resulting in a grade-level readability scale. ATOS uses three variables that include the number of characters and words per sentence in conjunction with the average grade level of those words to form its readability scale. While an in-depth discussion of the development of ATOS is beyond the scope of this paper (Milone, 2012), what makes ATOS different than other readability instruments is its inclusion of a graded word list compiled from a variety of sources that has been suggested to be the most extensive and accurate of its kind (Nelson et al., 2012). The list was developed using approximately 474 million words representing 28,000 fiction and nonfiction K-12 books in the Accelerated Reader quiz library and has been determined to be a valid and reliable measure of text readability (Nelson et al., 2012).

Narrative text readability. Consultation with ninth-grade English teachers at the study school resulted in the 
identification of a 408-word narrative passage from the story The Arabian Nights, (public domain text). It was selected as being representative of literature that ninth-grade students could be expected to read. Table 3 provides the quantitative assessment results. The passage graded at 9.5 on the Flesch-Kincaid scale (Flesch, 1951) and 9.0 on the ATOS Readability scale (Renaissance Learning, 2014). Using the Coh-Metrix on-line tool (Graesser, McNamara, Louwerse, \& Cai, 2004), the text was reflective of a narrative or story-like passage with a narrativity rating of 83 percent. The passage was written with low syntactic simplicity (2\%) meaning there are few clauses and words before the main verb. The text contains a high percentage of concrete words (90\%) making it easier to visualize. The passage was found to have moderately high sentence cohesion (76\%) and deep cohesion (64\%), both of which assist the reader with in-text scaffolding while reading.

Informational text readability. After considering several different texts, the passage considered best by the teachers was drawn from a book about Oliver Cromwell (public domain) and was assessed using multiple quantitative measurements of readability (Table 1 ). The passage consisted of 418 words and graded at the 9.23 grade level on the Flesch-Kincaid scale (Flesch, 1951) as measured by the Coh-Metrix on-line tool (Graesser et al., 2004), and at the 9.1 grade level using the ATOS Readability scale (Renaissance Learning, 2014). The CohMetrix tool (Graesser, McNamara, \& Kulkowich, 2011) found the text to be low in narrativity (22\%), meaning it is not story-like. The syntactic simplicity scale (79\%) reflected inconsistency at the phrase and part of speech level which places more demands on the reader, making comprehension processing more difficult (Crossley, Allen, \& McNamara, 2011). The passage contained an even percentage (50\%) of concrete and abstract words and was low in referential cohesion (24\%), resulting in little overlap of words and ideas between sentences. Texts low in referential cohesion can be challenging to understand for students with little prior knowledge about the topic. However, the passage was quite high (81\%) in deep cohesion meaning it contains an ample number of connecting words between ideas and events across the passage that can aid comprehension.

\subsection{Measured Variables}

A study of first-graders noted that a minimum of three, one-minute running record readings should be gathered to obtain stable measures of automaticity and accuracy (Fawson, Ludlow, Reutzel, Sudweeks, \& Smith, 2006). However, Valencia et al. (2010) found no differences in 1- versus 3-minute fluency measures for fourth and sixth graders. In order to obtain a reliable estimate of the measured variables and avoid possible measurement

Table 1. Qualitative and quantitative assessment results for narrative and informational texts.

\begin{tabular}{|c|c|c|}
\hline Measurement Type & Narrative Text & Informational Text \\
\hline \multicolumn{3}{|l|}{ Qualitative } \\
\hline Levels of meaning & Single level & Explicit \\
\hline Structure & Conventional structure & $\begin{array}{l}\text { Structure is less conventional; events related in } \\
\text { chronological order; chiefly informational content }\end{array}$ \\
\hline Language conventionality and clarity & Literal, clear & General academic and domain specific \\
\hline Knowledge demands & $\begin{array}{l}\text { Single theme; different from } \\
\text { reader's background }\end{array}$ & $\begin{array}{l}\text { Some experience with genre conventions required; } \\
\text { low intertextuality—no references to other texts }\end{array}$ \\
\hline \multicolumn{3}{|l|}{ Quantitative } \\
\hline Flesch-Kincaid grade-level* & 9.5 & 9.0 \\
\hline ATOS grade-level & 9.0 & 9.1 \\
\hline \multicolumn{3}{|l|}{ Coh-Metrix Readability measures: } \\
\hline Narrativity & 83\% (High) & $22 \%$ (Low) \\
\hline Syntactic simplicity & 2\% (Simple) & 79\% (Representative of informational text) \\
\hline Use of concrete words & 90\% (Liberal use) & 50\% (Evenly split with abstract words) \\
\hline Sentence cohesion & 76\% (High cohesion) & 24\% (Low cohesion) \\
\hline Deep cohesion & 64\% (Moderately good cohesion) & 81\% (High cohesion) \\
\hline
\end{tabular}

*Calculated using the Coh-Metrix online tool (Graesser, McNamara, Louwerse, \& Cai, 2004). 
differences attributable to text, we took a conservative approach and collected measures from readings that were three minutes in duration. Each measure is described below.

Accuracy. Accuracy is represented by the reader's number of deviations (miscues) from the printed text. Miscues consist of mispronounced words, words inserted into the text by the reader, and words that are in the text and skipped by the reader. Miscues that are self-corrected by the reader are not considered as deviations. Accuracy was calculated for each reading by counting the total number of miscues made across the 3-minute reading. The reader should keep in mind this variable is counter-intuitive; that is when reading accuracy improves the mean number of miscues decreases, reflecting the fact that the number of deviations from print has decreased. Conversely, a higher mean accuracy score reflects an increase in reading miscues.

Pacing. This measure is the total number of words read both correctly and otherwise during the 3-minute reading. Pacing provides an indication of the gross number of words processed by the reader during the assessment period.

Accumaticity. This measure is the mathematical difference between pacing and accuracy. For example, if pacing consisted of 380 words and total miscues equaled 21, accumaticity equals 359 (380 - 21). Accumaticity represents the number of words read correctly during the 3-minute reading.

\subsection{Group Assignment}

Research question one asks if the effect of text genre is different based on the extent to which a student is a fluent reader. The present study is part of a larger study involving multiple assessments, one of which is the Gray Oral Reading Test-4, Form A ([GORT] Wiederholt \& Bryant, 2001). The GORT is a standardized assessment that reports scale scores and percentiles as calculated by the test authors. To complete the GORT, the student reads a series of increasingly complex narrative reading passages while being monitored for pacing and word identification accuracy. One of the metrics arrived at by the GORT-4 is the difference between pacing and word accuracy, what we describe above as accumaticity. A scale score of 10 on the GORT indicates performance at the 50th percentile while a score of 9 indicates attainment at the 37th percentile. In this study we adopt the recommendations of Hock et al. (2009) who suggest that readers attaining at the 40th percentile and below be considered as struggling readers. As such, readers attaining an accumaticity score of 10 or higher on the GORT were coded as proficient readers, while those scoring 9 or less (37th percentile) were coded as struggling. This resulted in two groups of 34 proficient and 74 struggling readers. Internal consistency reliabilities reported by the test authors for the GORT-4 at the age-groups assessed in the present study are .92 for automaticity and .93 for both word identification accuracy, while test-retest reliabilities are equal to .95 and .92 , and .93 for accuracy and pacing respectively.

\subsection{Procedure}

Assessments were individually administered to participants by the study authors in a quiet room with the order of the assessments being rotated to avoid potential administration bias. Each administration required approximately 16 - 18 minutes. The GORT was administered per stated instructions in the Examiner's Manual where students began with an entry level passage reflective of their attained grade-level. Based on word accuracy and pacing scores, students either advanced to the next most difficult passage, or went back to the preceding and less difficult passage until competency reflected by a basal score was demonstrated. The assessment was discontinued once students reached pre-determined ceiling scores specified by the assessment administration instructions. For the narrative and informational passage readings, students were given instructions to read both using their normal reading voice. Readings were digitally recorded and later analyzed in order to obtain the pacing, word accuracy, and accumaticity measures. Students either read each passage through to completion or until the expiration of 3-minutes, whichever occurred first. To encourage reading with comprehension, students were given a brief one-sentence statement by the assessment administrator overviewing the general content of the story and told they may be asked about their reading upon completion.

\section{Results}

\subsection{Inter-Rater Reliability}

To obtain scores for the measured variables of pacing and accuracy for the two passages, each of the recorded 
readings was rated independently in a blind condition by the study authors. Any incongruence in scoring was then discussed and agreed upon by the scorers. Results were analyzed for inter-rater reliability using Cohen's kappa (Cohen, 1960; Fleiss, Levin, \& Paik, 2003) and resulted in a kappa equal to .95 suggesting high inter-rater reliability and scoring accuracy.

\subsection{Means and Correlations}

Table 2 displays the means and standard deviations for the measured variables. When considering differences by text genre, the means reveal differences between struggling and proficient students on all variables. For the measure of accuracy, struggling readers appear to be equally challenged by both genres while proficient readers appear less challenged with the informational text. For struggling readers, both pacing and accumaticity decrease when reading informational text. While proficient readers also show a decrease in both of these measures, the decrease appears to be slight, suggesting this group is less challenged by differences in text genre than those in the struggling reader group. Of note in Table 2 is the very close similarity in narrative and informational accuracy on the part of the struggling reader group. Table 3 shows the bivariate correlations for the measured variable with interpretations made using Hopkins (2006) scale where correlations between $.00-.09$ are trivial, $.10-.29$ are small, .30 - .49 are moderate, .50 - .69 are large, .70 - .89 are very large, and .90 and greater are nearly perfect. For both text-genres, accuracy shares a small to moderate negative relationship with both pacing and automaticity, suggesting that fewer miscues increase performance on both measures. Bivariate correlations between pacing and accumaticity are very large indicating a strong relationship between the two measures.

\subsection{Analysis}

This study investigates the extent to which the measures of accuracy, pace and accumaticity differ based on

Table 2. Means and standard deviations of the measured variables.

\begin{tabular}{|c|c|c|c|}
\hline & All Students ${ }^{\mathrm{a}}$ & Proficient Students ${ }^{\mathrm{b}}$ & Struggling Students ${ }^{\mathrm{c}}$ \\
\hline Text Genre & Mean (sd) & Mean (sd) & Mean (sd) \\
\hline GORT Fluency & 7.14 (3.77) & $11.71(2.55)$ & $5.05(1.93)$ \\
\hline Narrative Accuracy & $17.19(7.70)$ & $12.74(5.22)$ & $19.24(7.81)$ \\
\hline Narrative Pacing & 324.27 (86.69) & 403.29 (72.47) & $262.49(62.06)$ \\
\hline Narrative Accumaticity & $306.81(90.04)$ & 389.47 (76.75) & $268.82(67.63)$ \\
\hline Informational Accuracy & $16.01(10.52)$ & $9.24(7.02)$ & $19.12(10.42)$ \\
\hline Informational Pacing & $301.81(85.45)$ & 387.38 (64.38) & $287.96(66.31)$ \\
\hline Informational Accumaticity & $286.05(90.01)$ & 378.68 (63.74) & $243.49(64.86)$ \\
\hline
\end{tabular}

${ }^{\mathrm{a}} n=108 ;{ }^{\mathrm{b}} n=34 ;{ }^{\mathrm{c}} n=74$.

Table 3. Bivariate correlations of the measured variables.

\begin{tabular}{|c|c|c|c|c|c|c|}
\hline Variable & 1 & 2 & 3 & 4 & 5 & 6 \\
\hline Narrative Accuracy & 1 & & & & & \\
\hline Narrative Pacing & $-.284 * *$ & 1 & & & & \\
\hline Narrative Accumaticity & $-.367 * *$ & $.989 * *$ & 1 & & & \\
\hline Informational Accuracy & $.753 * *$ & $-.292 * *$ & $-.337 * *$ & 1 & & \\
\hline Informational Pacing & $-.280 * *$ & $.854 * *$ & $.822 * *$ & $-.366^{* *}$ & 1 & \\
\hline Informational Accumaticity & $-.352 * *$ & $/ 846^{* *}$ & $.821^{* *}$ & $-.461 * *$ & $.994 * *$ & 1 \\
\hline
\end{tabular}
$* * p<.01$. 
whether the student is reading narrative or informational genre. For all analyses a Bonferroni adjustment was applied to the resulting $t$-tests to control for inflated experimenter-wise error (Fields, 2009).

\subsection{Reader Groups}

As described previously, two reader groups were formed based on the accumaticity score obtained from the GORT. The struggling reader group $(n=74)$ attained a mean score of $5.1(1.93)$ with the median equal to 5.0, equating to approximately the 7th percentile as reported by the GORT test authors. The proficient reader group $(n=34)$ attained a mean score of 11.7 (2.55) with a median equal to 11.0, equating to the 75th percentile.

\subsection{Research Question One}

Research question one asks, when considering all students $(n=108)$, do differences exist in the measured variables by text-genre? To answer this question, three paired-sample $t$-tests comparing narrative and informational accuracy, pacing, and accumaticity were conducted. Results (Table 4) reveal no statistically significant difference in reading accuracy by text genre. However, pacing was significantly slower with small effects sizes when students read informational text, $t(107)=5.02, p<.001, d=.26$. A similar decrease was found for accumaticity, $t(107)=4.00, p<.001, d=.23$.

\subsection{Research Question Two}

Research question two asks to what extent do struggling and proficient readers differ on measures of accuracy, pacing, and accumaticity when reading narrative and informational text?

We conducted a series of paired-sample $t$-tests using pacing, accuracy, and accumaticity as the dependent variables for the proficient and struggling reader groups. Table 4 shows that for the proficient reader group, no statistically significant difference was found in either pacing or accumaticity attributable to text genre. However, statistically significant results with large effects were found for reading accuracy, $t(33)=3.81, p<.05, d=.58$, with inspection of the means (Table 2) showing proficient students made fewer miscues than did those in the struggling reader group when reading informational text. For the struggling reader group, statistically significant differences were found for pacing where students read narrative text more quickly than informational, $t(73)=$ $7.15, p<.001, d=0.40$, and for accumaticity where narrative text was also read more quickly than informational, $t(73)=6.55, p<.001, d=0.39$. No significant differences attributable to text-genre were found for accuracy in the struggling reader group.

\subsection{Research Question Three}

Research question three asks whether proficient and struggling readers differ on the three measured variables by text-genre. To investigate this question we conducted an analysis of variance (ANOVA) test for each of the three variables using group as the between factor. To account for the unequal group size, Levene's test for equality of variances was first conducted with a statistically significant test occurring only for the variable of accuracy, $F(106)=18.38, p<.001$, resulting in an adjustment to the degrees of freedom. Results (Table 5) revealed that when reading narrative text, statistically significant differences between proficient and struggling readers with very large effects were found for accuracy, $F(1,101.06)=19.52, p<.001, d=.92$, pacing, $F(1,106)$ $=66.45, p<.001, d=1.71$, and accumaticity, $F(1,106)=68.04, p<.001, d=1.72$. Inspection of the means

Table 4. Results of paired sample $t$-tests for within-group differences by text genre.

\begin{tabular}{ccccccc}
\hline & \multicolumn{2}{c}{ All Students $^{1}$} & \multicolumn{2}{c}{ Proficient Readers $^{2}$} & \multicolumn{2}{c}{ Struggling Readers $^{3}$} \\
\hline Variable & $t(d f)$ & $d$ & $t(d f)$ & $d$ & $t(d f)$ & $d$ \\
\hline Accuracy & $1.78(107)$ & & $3.81(33)^{* *}$ & 0.58 & $.14(73)$ \\
Pacing & $5.02(107)^{* * *}$ & 0.26 & $1.33(33)$ & & $7.15(73)^{* * *}$ & 0.40 \\
Accumaticity & $4.00(107)^{* * *}$ & 0.23 & $.76(33)$ & $6.55(73)^{* * *}$ & 0.39 \\
\hline
\end{tabular}

${ }^{* *} p<.01 ;{ }^{* * *} p<.001 .{ }^{1} n=108 ;{ }^{2} n=34 ;{ }^{3} n=74$. 
Table 5. Results of analysis of variance (ANOVA) for between-group (proficient/struggling) differences by text-genre.

\begin{tabular}{ccccc}
\hline & Narrative & \multicolumn{2}{c}{ Informational } \\
\hline Variable & $F(d f)$ & $d$ & $F(d f)$ & $d$ \\
\hline Accuracy & $19.52(1,106)^{* * *}$ & .92 & $25.25(1,106)^{* * *}$ & 1.05 \\
Pacing & $66.45(1,106)^{* * *}$ & 1.71 & $92.17(1,106)^{* * *}$ & 2.01 \\
Accumaticity & $68.04(1,106)^{* * *}$ & 1.72 & $102.31(1,106)^{* * *}$ & 2.12 \\
\hline
\end{tabular}

$* * * p<.001$.

show that proficient readers outscored the struggling group. For informational texts, results (Table 5) show statistically significant differences for all three variables with very large effects for accuracy, $F(1,106)=25.25, p$ $<.001, d=1.05$, pacing, $F(1,106)=92.17, p<.001, d=2.01$, and accumaticity, $F(1,106)=102.31, p<.001, d$ $=2.12$. Again, the scores of proficient readers exceeded those who struggled.

\section{Discussion}

Graesser, Golding, \& Long (1991) have posited that unfamiliar and more complicated genre structures makes informational text potentially more difficult to read than narrative genres. To explore this assertion the present study investigated the extent to which fluent reading behaviors of ninth-grade students were influenced by text genre. Students read both narrative and informational genres (408 and 418 words long respectively) until the expiration of 3 minutes. Both text genres were subjected to readability evaluations using criteria recommended by Appendix A of the CCSS (2010), the results of which clearly distinguished one as narrative and the other as informational. First, this study found that pacing and accumaticity were slower when students read informational text, while both were read with no differences in accuracy. Second, when readers were identified as either proficient or struggling, between-group analyses found that proficient readers were more accurate when reading the informational text, however, no differences were found for pacing or accumaticity. Struggling readers on the other hand, showed no difference in reading accuracy between the two text genres; however, significant differences with large effect sizes were found in favor of narrative text, meaning informational text was read more slowly. Finally, when proficient and struggling readers were compared for differences by text genre, proficient readers showed greater facility with both texts on all three measures with large to very large effect sizes.

These findings suggest at least two conclusions. First, no differences were found for word identification accuracy for the entire study sample. A deeper analysis of word accuracy finds metrics of 94.9\% (19.81/391.28) and $94.5 \%$ (19.94/367.35) for narrative and informational genres respectively. These percentages closely approximate the accepted wisdom that 95\% accuracy represents an instructional level text, thus suggesting that with the texts used in the present study, this sample of ninth-grade students could accurately decode words. Analysis by reader group found that while proficient readers read informational text with greater accuracy, their percent of words read correctly for both text genres exceeded the $95 \%$ threshold for independent reading. At this point we remind the reader that the struggling reader group attained a mean score equivalent to the 5th percentile on the Gray Oral Reading Test, a standardized assessment of fluent reading behaviors, while the proficient reader group attained a mean equal to the 75th percentile. When we analyze decoding accuracy for the struggling reader group, we see they attained 94\% (22.64/376.63) and 93.3\% (23.63/348.36) with narrative and informational text respectively, with no statistical difference between the two means. This evidence suggests that the source of difficulty for these students resides not in poor word recognition accuracy, but in languid pacing. The question is then raised as to the source of this pacing difficulty?

The second conclusion of the present study is that struggling readers exhibit significant differences in the pace in which they read informational versus narrative genres. Such a difference in pace translates to slower accumaticity for struggling readers. Pacing is reflective of the reader's ability to process connected text, what is also referred to as reading rate. A slower reading pace may indicate excessive use of cognitive resources in order to recognize words and a decrease in reading comprehension; hence as readers become more automatic in recognizing and retrieving words, their accumaticity with (and comprehension of) the entire text will improve (LaBerge \& Samuels, 1974; Perfetti, 1985, 1988). Of course an excessively fast reading rate may become counter- 
productive to reading comprehension and thus the suggestion that a conversational rate balances the pace of decoding with comprehension processing. So the question becomes the source of narrative and informational pacing differences found by the present study in struggling readers? We think some insight can be gained by revisiting the text readability metrics identified earlier as cognitive psychologists suggest they may well influence reading accumaticity (Graesser et al., 1991).

Using textual characteristics computed by the Coh-Metrix Text Easability Assessor (Graesser et al., 2011), the narrative passage was found to be low in syntactic simplicity, high in narrativity, high in sentence cohesion and written with a liberal use of concrete words which gives it an easier to read, story-like quality. The informational text on the other hand, was found to possess high syntactic complexity, low narrativity and little sentence coherence, as well as a 50 percent split between concrete and abstract words, thus making the text very different from the typical story structure. Keeping in mind the poor accumaticity skills of the struggling reader group as reflected by the low mean on the GORT, we propose that the differences in textual characteristics may account to a large extent, for the slower pacing accumaticity scores found for informational text. We base this on research suggesting that more syntactically complex texts are more difficult to parse and process as they depart from the more familiar syntactic structures found in frequently used spoken and narrative-text language (Ashcraft, 2006; Alexander \& Jetton, 2003; Graesser et al., 1991; Perfetti, 1990; Rayner et al., 2012). Given the poor level of reading achievement by the struggling reader group, it is not a stretch to surmise that they have considerably less experience reading text and, as such, have not engaged in the requisite practice that promotes fluent reading behaviors (Anderson, Wilson, \& Fielding, 1988; Anderson, Hiebert, Wilkinson, \& Scott, 1985). This difficulty manifests itself in the decreased accumaticity scores found for informational text. Thus, the findings of the present study lend support to the model proposed by Graesser et al. (1997) suggesting the strong influence of compositional components by text-genre on the ability to read text.

While the compositional components discussed above are hypothesized to be the source of decreased pacing and accumaticity scores, the tandem theory of reading (Paige et al., 2014) hypothesizes that when reading and monitoring for comprehension, the reader may adjust their reading pace as necessary to facilitate comprehension. Our results also provide support for the tandem theory as pacing and accumaticity were significantly slower for informational text, suggesting the possibility that the reader found it necessary to adjust pacing to compensate for increased comprehension processing needs demanded by the compositional components related to text genre. Results for the group of 27 proficient readers found large effects for differences in word accuracy with informational text being read with fewer miscues. To keep this in perspective, $98 \%$ of the words in the informational text were read correctly compared to $97.4 \%$ of the words in the narrative text. What is perhaps more interesting is that there were no significant differences in pacing or accumaticity attributable to text-genre. This suggests that in this relatively small sample of readers, the differences between narrative and informational text accounted for by the compositional components identified by Graesser et al. (1997) made no difference in pacing and accumaticity for this group of proficient readers. Our data provides us with no basis from which to make an empirical claim for this result so we can only speculate that this particular reader group may as a whole, have experience with the type of informational text presented to them in this study. As such, their prior experience with similar text supported their reading to the point where no effect on pacing or accumaticity was found.

\subsection{Instructional Implications}

One of the key shifts in the Common Core State Standards (CCSS) for grades K-5 is to provide a 50 - 50 balance between literary and informational genre reading. In grades 6 - 12, the CCSS places greater emphasis on the specific category of literary nonfiction within the ELA classrooms and within each discipline incorporates reading history/social studies, science, and the technical subjects. Across grade and content areas, the goal of this key shift from traditional standards is to build student knowledge through the use of content-rich nonfiction. In order to be a proficient reader who is also college- and career-ready, students must possess strong general knowledge and vocabulary, and be immersed in information about the world around them. In light of the research from the present study, we posit that struggling students need additional support in subject area classrooms in the development of fluent reading with informational text in order to sufficiently access necessary background knowledge.

A growing body of evidence, mostly from studies conducted with elementary-grade students, has demonstrated that instruction in reading fluency can lead to improvements in fluent reading, comprehension, and over- 
all reading proficiency (Paige, 2011a). We advocate that the same principles can be applied to development of fluency with nonfiction text to improve comprehension and overall reading proficiency, especially for those who struggle with fluency at the secondary level. One suggestion is to incorporate into content area classes instructional strategies to develop fluency. Content taught in these classes often involves instruction such as in-class silent reading and teacher read-alouds. These can be opportunities to incorporate strategies using the content to address fluency with the goal of fostering comprehension to build background knowledge. Examples of such strategies include deep (repeated) and wide reading (Rasinski, 2010) and assisted reading through such activities as buddy, echo, or choral/unison reading (Paige, 2011b, 2011c; Topping, 1987, 2005). In a study of seventh-graders where content text was used to engage students in short, daily choral readings, Paige (2008) found that students were better able to acquire initial background knowledge that enabled deeper teaching and learning of science through the melding of fluency instruction with the content.

Reading rate or pacing has become a ubiquitous measure of accumaticity in reading. The extant norms for assessing accumaticity do not differentiate between narrative and informational genres. Given the substantial differences in accumaticity between narrative and informational genres found in the present study, differential norms should be developed for narrative and informational text reading. At the very least, the present study suggests that norms for informational texts are approximately $90 \%$ of the corresponding narrative norms.

\subsection{Conclusion}

Our study results highlight the differences that make the fluent reading of informational text more difficult than reading of narrative text for a group of students attending a metropolitan, inner-city school. With only a few exceptions, it's important to note that the 108 students forming the study population do not possess diagnosed reading disabilities. Rather, the study population consists of inner-city students, many of whom have not developed adequate reading fluency. We suggest that because the frequency of reading miscues with grade-level text is in the instructional range for the students in the present study, these students do possess a considerable amount of phonics/word recognition knowledge. Accumaticity or pacing, however, appears to be a major concern.

In a recent investigation of secondary literacy practices conducted within the present study school site, results show that few disciplinary teachers incorporate literacy practices into their instruction, while no teachers engage their students in instruction to improve reading fluency (Paige \&Magpuri-Lavell, 2011a). Hence, it is our contention that minimal attention within the curriculum to fluent reading instruction is a plausible explanation for the outcomes found in this study. Providing more intensive support for disciplinary teachers in the teaching of reading in general and fluency in particular may help to improve fluency and literacy outcomes for all students.

Our results also highlight the disparity between narrative and informational fluency in the study population and suggest the need for increased attention to develop fluent reading with informational text. With the intensified focus by the Common Core State Standards (2010) on the reading of informational text, new attention must be directed to the fluent reading of such text. This strongly implies that disciplinary teachers must become involved in assisting their students with strategies to encourage fluent reading.

\subsection{Study Limitations}

The reader should keep in mind that the population under study is not reflective of a typical and normally achieving ninth-grade sample. Rather, the population is much more typical of inner city students from backgrounds of poverty. As such, the generalizability of these results should not be extended to ninth-grade students in general. The narrative and informational texts used to gather the study measures have not been shown to be valid and reliable and so caution should be used when interpreting their results. Also, the constraints surrounding the selection of study participants prohibited the random selection of subjects. Thus, a convenience sample was assembled which limits the generalizability of the study results.

\subsection{Future Research}

With the emphasis by the Common Core State Standards on the fluent reading of text, and particularly informational text, there is a need to further understand how readers differ in their reading with these two text genres. As the results of this study show, it cannot be assumed that readers will be equally fluent with narrative and informational text. Future studies can focus on examining fluency differences between text-types in lower grades, 
particularly in later elementary and middle school. Studies of normally attaining readers are also needed to determine if the differences found in the present study exist in samples that are more representative of typically fluent readers. Additionally, informational texts from other areas of social studies, as well as areas such and science and mathematics, will also serve to further inform how students read informational text.

\section{Acknowledgements}

The open access publishing fees for this article have been covered by the Texas A\&M University Online Access to Knowledge (OAK) Fund, supported by the University Libraries and the Office of the Vice President for Research.

\section{References}

ACT (2013). The Condition of College and Career Readiness 2013. Iow City, IA: ACT.

Alexander, P. A., \& Jetton, T. L. (2003). Learning from Traditional and Alternative Texts: New Conceptualizations for the Information Age. In A. C. Graesser, M. A. Gernsbacher, \& S. R. Goldman (Eds.), Handbook of Discourse Processes (pp. 83-121). Upper Saddle River, NJ: Erlbaum.

Anderson, R. C., Hiebert, E. H., Wilkingson, I. A. G., \& Scott, J. (1985). Becoming a Nation of Readers: The Report of the Commission on Reading. Washington, DC: National Institute of Education.

Anderson, R. C., Wilson, P. T., \& Fielding, L. G. (1988). Group Reading and How Children Spend Their Time outside of School. Reading Research Quarterly, 23, 285-303. http://dx.doi.org/10.1598/RRQ.23.3.2

Ashcraft, M. (2006). Cognition (4th ed.). Upper Saddle River, NJ: Pearson.

Bader, M. (1998). Prosodic Influences of Reading Syntactically Ambiguous Sentences. In J. Fodor, \& F. Ferreira (Eds.), Reanalysis in Sentence Processing (pp. 1-46). Dordrecht: Kluwer. http://dx.doi.org/10.1007/978-94-015-9070-9_1

Best, R. M., Floyd, R. G., \& McNamara, D. (2008). Differential Competencies Contributing to Children's Comprehension and Narrative and Expository Texts. Reading Psychology, 29, 137-164. http://dx.doi.org/10.1080/02702710801963951

Braten, I., \& Oistein, A. (2013). Does Natural Occurring Comprehension Strategies Instruction Make a Difference When Students Read Expository Text? Journal of Research in Reading, 36, 42-57. http://dx.doi.org/10.1111/j.1467-9817.2011.01489.x

Cervetti, G. N., Bravo, M. A., Hiebert, E. H., Pearson, P. D., \& Jaynes, C. A. (2009). Text Genre and Science Content: Ease of Reading, Comprehension, and Reader Preference. Reading Psychology, 30, 487-511. http://dx.doi.org/10.1080/02702710902733550

Chall, J. S. (1983). Stages of Reading Development. New York: McGraw-Hill.

Cohen, J. A. (1960). A Coefficient of Agreement for Nominal Scales. Educational and Psychological Measurement, 20, 3746. http://dx.doi.org/10.1177/001316446002000104

College Board (2014). The 2014 SAT Report on College and Career Readiness. New York: Author. http://research.collegeboard.org/programs/sat/data/archived/cb-seniors-2014

Common Core State Standards (2010). Common Core State Standards for English Language Arts \& Literacy in History/Social Studies, Science, and Technical Subjects. Washington DC: CCSSOO \& National Governors Association. http://www.corestandards.org/assets/Appendix_A.pdf

Crossley, S. A., Allen, D. B., \& McNamara, D. S. (2011). Text Readability and Intuitive Simplification: A Comparison of Readability Formulas. Reading in a Foreign Language, 23, 84-101.

Daane, M. C., Campbell, J. R., Grigg, W. S., Goodman, M. J., \& Oranje, A. (2005). Fourth-Grade Students Reading Aloud: NAEP 2002 Special Study of Oral Reading. Washington DC: U.S. Department of Education, Institute of Education Sciences and U.S. Government Printing Office.

Diakidoy, I., Stylianou, P., Karefillidou, C., \& Papageorgiou, P. (2004). The Relationship between Listening and Reading Comprehension of Different Types of Text at Increasing Grade Levels. Reading Psychology an International Quarterly, 26, 55-80. http://dx.doi.org/10.1080/02702710590910584

Elkind, J. (1998). Computer Reading Machines for Poor Readers. Report 9801, Portola Valley, CA: Lexia Institute. www.kurzweiledu.com

Fawson, P. C., Ludlow, B. C., Reutzel, D. R., Sudweeks, R., \& Smith, J. A. (2006). Examining the Reliability of Running Records. Attaining Generalizable Results. Journal of Educational Research, 100, 113-16. http://dx.doi.org/10.3200/JOER.100.2.113-126

Fields, A. (2009). Discovering Statistics Using SPSS (3rd ed.). London: Sage. 
Fleiss, J. L., Levin, B., \& Paik, M. C. (2003). Statistical Methods for Rates and Proportions. Hoboken, NJ: Wiley. http://dx.doi.org/10.1002/0471445428

Flesch, R. F. (1951). How to Test Readability. New York: Harper.

Fodor, J. D. (2002). Prosodic Disambiguation in Silent Reading. In M. Hirotani (Ed.), Proceedings of the North East Linguistics Society (Vol. 32, pp. 112-132). Amherst, MA: GSLA.

Fuchs, L. S., Fuchs, D., Hosp, M. K., \& Jenkins, J. R. (2001). Oral Reading Fluency as an Indicator of Reading Competence: A Theoretical, Empirical, and Historical Analysis. Scientific Studies of Reading, 5, 239-256. http://dx.doi.org/10.1207/S1532799XSSR0503_3

Goldman, S. R., \& Rakestraw, J. S. (2000). Structural Aspects of Constructing Meaning from Text. In M. L. Kamil, P. B. Mosenthal, P. D. Pearson, \& R. Barr (Eds.), Handbook of Reading Research (Vol. 3, pp. 311-335). Mahwah, NJ: Lawrence Erlbaum.

Graesser, A. C., \& McNamara, D. S. (2011). Computational Analyses of Multilevel Discourse Comprehension. Topics in Cognitive Science, 3, 371-398. http://dx.doi.org/10.1111/j.1756-8765.2010.01081.x

Graesser, A. C., McNamara, D. S., \& Kulikowich, J. M. (2011). Coh-Metrix: Providing Multilevel Analysis of Text Characteristics. Educational Researcher, 40, 223-234. http://dx.doi.org/10.3102/0013189X11413260

Graesser, A. C., McNamara, D. S., Louwerse, M. M., \& Cai, Z. (2004). Coh-Metrix: Analysis of Text on Cohesion and lAnguage. Behavior Research Methods, Instruments, and Computers, 36, 193-202. http://dx.doi.org/10.3758/BF03195564

Graesser, A. C., Millis, K. K., \& Zwaan, R. A. (1997). Discourse Comprehension. Annual Review of Psychology, 48, 163190. http://dx.doi.org/10.1146/annurev.psych.48.1.163

Graesser, A., Golding, J., \& Long, D. L. (1991). Narrative Representation and Comprehension. In R. Barr, M. L. Kamil, P. Mosenthal, \& P. D. Pearson (Eds.), Handbook of Reading Research (Vol. 2, pp. 171-205). Mahwah, NJ: Erlbaum.

Hock, M. F., Brasseur, D. D., Catts, H. W., Marquis, J. G., Mark, C. A. et al. (2009). What Is the Reading Component Skill Profile of Adolescent Struggling Readers in Urban Schools? Learning Disability Quarterly, 32, 21-38.

Hooley, D. S., Tysseling, L. A., \& Ray, B. (2013). Trapped in a Cycle of Low Expectations: An Exploration of High School Seniors' Perspectives about Academic Reading. The High School Journal, 96, 321-338. http://dx.doi.org/10.1353/hsj.2013.0018

Hoover, W. A., \& Gough, P. B. (1990). The Simple View of Reading. Reading and Writing: An Interdisciplinary Journal, 2 , 127-160. http://dx.doi.org/10.1007/BF00401799

Hopkins, W. B. (2006). A Scale of Magnitudes for the Effect Statistics: A New View of Statistics. http://www.sportssci.org/resource/stats/effectmag.html

Jenkins, J. R., Fuchs, L. S., Espin, C., van den Broek, P., \& Deno, S. L. (2003a). Sources of Individual Differences in Reading Comprehension and Reading Fluency. Journal of Educational Psychology, 95, 719-729. http://dx.doi.org/10.1037/0022-0663.95.4.719

Jenkins, J. R., Fuchs, L. S., Espin, C., van den Broek, P., \& Deno, S. L. (2003b). Accuracy and Fluency in List and Context Reading of Skilled and RD Groups: Absolute and Relative Performance. Learning Disabilities: Research and Practice, 18, 237-245. http://dx.doi.org/10.1111/1540-5826.00078

Just, M. A., \& Carpenter, P. A. (1980). A Theory of Reading: From Eye Fixations to Comprehension. Psychological Review, 87, 329-354. http://dx.doi.org/10.1037/0033-295X.87.4.329

Kelley, M., \& Clausen-Grace, N. (2006). R5: The Sustained Silent Reading Makeover That Transformed Readers. The Reading Teacher, 60, 148-157. http://dx.doi.org/10.1598/RT.60.2.5

Kim, J. S., \& White, T. G. (2008). Scaffolding Voluntary Summer Reading for Children in Grades 3 to 5: An Experimental Study. Scientific Studies of Reading, 12, 1-23. http://dx.doi.org/10.1080/10888430701746849

Kucan, L., \& Beck, I. (1996). Fourth Grades Thinking Aloud: An Investigation of Genre Effects. Journal of Literacy Research, 28, 259-287. http://dx.doi.org/10.1080/10862969609547921

Kuhn, M. R., \& Stahl, S.A. (2003). Fluency: A Review of Developmental and Remedial Practices. Journal of Educational Psychology, 95, 3-21. http://dx.doi.org/10.1037/0022-0663.95.1.3

LaBerge, D., \& Samuels, S. J. (1974). Toward a Theory of Automatic Information Processing in Reading. Cognitive Psychology, 6, 293-323. http://dx.doi.org/10.1016/0010-0285(74)90015-2

Langer, J. A. (1986). Relations between Levels on Prior Knowledge and the Organization of Recall. In M. L. Kamil, \& A. J. Moe (Eds.), Perspectives in Reading Research and Instruction. Washington, DC: National Reading Conference.

Lewin, T. (2014). A New SAT Aims to Realign with Schoolwork. The New York Times. http://www.nytimes.com/2014/03/06/education/major-changes-in-sat-announced-by-college-board.html? _r=0

McCormick, C., \& Samuels, S. J. (1979). Word Recognition by Second Graders: The Unit of Perception and Interrelation- 
ships among Accuracy, Latency, and Comprehension. Journal of Reading Behaviour, 11, 107-108. http://dx.doi.org/10.1080/10862967909547314

Meyer, B. J. F., \& Rice, G. E. (1984). The Structure of Text. In P. D. Pearson, R. Barr, M. L. Kamil, \& P. Mosenthal (Eds.), Handbook of Reading Research (pp. 319-351). New York: Longman.

Milone, M. (2012). The Development of ATOS: The Renaissance Readability Formula. Wisconsin Rapids, WI: Renaissance Learning.

National Center for Education Statistics (2013). The Nation's Report Card: A First Look: 2013 Mathematics and Reading (NCES 2014-451). Washington DC: Institute of Education Sciences, U.S. Department of Education.

National Governors Association Center and Council of Chief State School Officers (2012). Common Core State Standards Initiative. http://www.corestandards.org/in-the-states

Nelson, J., Perfetti, C., Liben, D., \& Liben, M. (2012). Measures of Text Difficulty: Testing Their Predictive Value for Grade Levels and Student Performance. New York, NY: Student Achievement Partners.

Olson, G. M., Mack, R. L., \& Duffy, S. A. (1981). Cognitive Aspects of Genre. Poetics, 10, 283-315. http://dx.doi.org/10.1016/0304-422X(81)90039-5

Paige, D. D. (2008). An Evaluation of Whole-Class Choral Reading Using Science Text on Oral Reading Fluency in Struggling Adolescents. Unpublished Doctoral Dissertation, Memphis: University of Memphis.

Paige, D. D. (2011a). Engaging Struggling Adolescent Readers through Situational Interest: A Model Proposing the Relationships among Extrinsic Motivation, Oral Reading Fluency, Comprehension, and Academic Achievement. Reading Psychology, 32, 395-425. http://dx.doi.org/10.1080/02702711.2010.495633

Paige, D. D. (2011b). 16 Minutes with “Eyes-on-Text” Can Make a Difference: Whole-Class Choralreading as an Adolescent Reading Strategy. Reading Horizons, 51, 1-20.

Paige, D. D. (2011c). That Sounded Good! Using Whole-Class Choral Reading to Improve Fluency. The Reading Teacher, 64, 435-438. http://dx.doi.org/10.1598/RT.64.6.5

Paige, D. D., \& Magpuri-Lavell, T. (2011a). Exploring Secondary Literacy Instruction: What Students Need and What Teachers Practice. Unpublished Manuscript.

Paige, D. D., \& Magpuri-Lavell, T. (2011b). Unpacking Adolescent Literacy Skills in a High-Poverty, Urban High School. In T. Morrison, L. Martin, M. Boggs, \& S. Szabo (Eds.), Literacy Promises: The Thirty-Third Yearbook, a Double Peer Reviewed Publication of the Association of Literacy Educators and Researchers (Vol. 33, pp. 219-236). Association of Literacy Educators and Researchers: Corpus Christi. http://c.ymcdn.com/sites/www.aleronline.org/resource/resmgr/yearbooks/yearbook_volume_33.pdf

Paige, D. D., Rasinski, T. V., \& Magpuri-Lavell, T. (2012). Is Fluent Expressive Reading Important for High School Readers? Journal of Adult and Adolescent Literacy, 56, 67-76. http://dx.doi.org/10.1002/JAAL.00103

Paige, D. D., Rasinski, T. V., Magpuri-Lavell, T., \& Smith, G. S. (2014). Interpreting the Relationships among Prosody, Automaticity, Accuracy, and Silent Reading Comprehension in Secondary Students. Journal of Literacy Research, 46, 123-156. http://dx.doi.org/10.1177/1086296x14535170

Perfetti, C. A. (1985). Reading Ability. New York: Oxford Press.

Perfetti, C. A. (1988). Verbal Efficiency in Reading Ability. In M. Daneman, G. E. MacKinnon, \& T. G. Waller (Eds.), Reading Research: Advances in Theory and Practice (pp. 109-143). New York: Academic Press.

Perfetti, C. A. (1990). The Cooperative Language Processors: Semantic Influences in an Autonomous Syntax. In D. A. Balota, C. B. Flores d'Arcais, \& K. Raynor (Eds.), Comprehension Processes in Reading (pp. 205-230). Hillsdale, NJ: Erlbaum.

Pinnell, G. S., Pikulski, J. J., Wixon, K. K., Campbell, J. R., Gough, P. B., \& Beatty, A. S. (1995). Listening to Children Read Aloud. Washington DC: Office of Educational Research and Improvement, U.S. Department of Education.

Rasinski, T. V. (2010). The Fluent Reader: Oral and Silent Reading Strategies for Building Word Recognition, Fluency, and Comprehension (2nd Edition). New York: Scholastic.

Rasinski, T. V., Padak, N. C., McKeon, C. A., Wilfong, L. G., Friedauer, J. A., \& Heim, P. (2005). Is Reading Fluency a Key for Successful High School Reading? Journal of Adolescent and Adult Literacy, 49, 22-27.

http://dx.doi.org/10.1598/JAAL.49.1.3

Rayner, K., Pollatsek, A., Ashby, J., \& Clifton Jr., C. (2012). Psychology of Reading. New York: Psychology Press.

Read, S., Reutzel, D. R., \& Fawson, P. C. (2008). Do You Want to Know What I Learned? Using Informational Trade Books as Models to Teach Text Structure. Early Childhood Education Journal, 36, 213-219.

http://dx.doi.org/10.1007/s10643-008-0273-0

Renaissance Learning (2014). https://www.renaissance.com/about-us 
Reutzel, D. R., Fawson, P. C., \& Smith, J. A. (2008). Reconsidering Silent Sustained Reading: An Exploratory Study of Scaffolded Silent Reading (ScSR). Journal of Educational Research, 102, 37-50. http://dx.doi.org/10.3200/JOER.102.1.37-50

Reutzel, D. R., Jones, C. D., Fawson, P. C., \& Smith, J. A. (2008). Scaffolded Silent Reading (ScSR): An Alternative to Guided Oral Repeated Reading that Works! The Reading Teacher, 62, 194-207.

Rupley, W. H., \& Slough, S. (2010). Building Prior Knowledge and Vocabulary in Science in the Intermediate Grades: Creating Books for Learning. Literacy Research and Instruction, 49, 99-112. http://dx.doi.org/10.1080/19388070902780472

Sáenz, L. M., \& Fuchs, L. S. (2002). Examining the Reading Difficulty of Students with Learning Disabilities. Remedial and Special Education, 23, 31-41. http://dx.doi.org/10.1177/074193250202300105

Samuels, S. J., \& Farstrup, A. E. (2006). What Research Has to Say about Fluency Instruction. Newark, DE: International Reading Association.

Schatschneider, C., Buck, J., Torgesen, J. K., Wagner, R. K., Hassler, L., Hecht, S. et al. (2004). A Multivariate Study of Factors That Contribute to Individual Differences in Performance on the Florida Comprehensive Reading Assessment Test. Technical Report No. 5, Tallahassee: Florida Center for Reading Research.

Slowiaczek, M. L., \& Clifton Jr., C. (1980). Subvocalization and Reading for Meaning. Journal of Verbal Learning and Verbal Behavior, 19, 573-582. http://dx.doi.org/10.1016/S0022-5371(80)90628-3

Spiro, R. J., \& Taylor, B. M. (1980). On Investigating Children's Transition from Narrative to Expository Discourse: The Multidimensional Nature of Psychological Text Classification. Technical Report No. 195, University of Illinois: Center for the Study of Reading. http://eric.ed.gov/?q=expository+and+narrative+text+reading\&pg=10\&id=ED199666

Stecker, S. K., Roser, N. L., \& Martinez, M. G. (1998). Understanding Oral Reading Fluency. In T. Shanahan, \& F. V. Rodriquez-Brown (Eds.) 47th Yearbook of the National Reading Conference (pp. 295-310). Chicago: National Reading Conference.

Stein, N. L., \& Trabasso, T. (1981). What's in a Story: An Approach to Comprehension and Instruction. In R. Glaser (Ed.), Advances in the Psychology of Instruction (Vol. 2, pp. 213-267). Hillsdale, NJ: Erlbaum.

Taylor, S. (2011). Exploring Silent Reading Fluency: Its Nature and Development. Springfield, IL: Thomas.

Topping, K. J. (1987). Peer Tutored Paired Reading: Outcome Data from Ten Projects. Educational Psychology, 7, $133-145$. http://dx.doi.org/10.1080/0144341870070206

Topping, K. J. (2005). Trends in Peer Learning. Educational Psychology, 25, 631-645. http://dx.doi.org/10.1080/01443410500345172

Valencia, S. W., Smith, A., Reece, A. M., Li, M., Wixson, K. K., \& Newman, H. (2010). Oral Reading Fluency Assessment: Issues of Construct, Criterion, and Consequent Validity. Reading Research Quarterly, 45, 270-291. http://dx.doi.org/10.1598/RRQ.45.3.1

Walther, M., Frazier, L., Clifton Jr., C., Hemforth, B., Konieczny, L., \& Seelig, H (1999). Prosodic and Syntactic Effects on Relative Clause Attachments in German and English. Poster Presented at AMLaP 99, Edinburgh, Scotland.

Weaver, C. A., \& Kintsch, W. (1991). Expository Text. In R. Barr, M. L. Kamil, P. Mosenthal, \& P. D. Pearson (Eds.), Handbook of Reading Research (Vol. 2, pp. 230-245). Mahwah, NJ: Lawrence Erlbaum.

Wiederholt, J. L., \& Bryant, B. R. (2001). Gray Oral Reading Test (4th ed.). Austin, TX: Pro-Ed.

Young, A. R., Bowers, P. G. \& MacKinnon, G. E. (1996). Effects of Prosodic Modeling and Repeated Reading on Poor Readers' Fluency and Comprehension. Applied Psycholinguistics, 17, 59-84.

http://dx.doi.org/10.1017/S0142716400009462 